\title{
TERAPIA FOTODINÂMICA EM ELETROFIAÇÃO: REVISÃO DE TÉCNICAS E APLICAÇÕES
}

\author{
Ariane R. de S. Rossin ${ }^{a}$, Évelin Lemos de Oliveira ${ }^{a}$, Flavia Amanda Pedroso de Moraes ${ }^{a}$, Ranulfo C. da S. Júniora ${ }^{\text {, Desirée }}$ \\ Tamara Scheidt ${ }^{\mathrm{b}}$, Wilker Caetano ${ }^{\mathrm{a}}$, Noboru Hioka ${ }^{\mathrm{a}, *}$ e Douglas C. Dragunski ${ }^{\mathrm{b}, *,(\mathbb{D}}$ \\ a'Departamento de Química, Universidade Estadual de Maringá, 87020-900 Maringá - PR, Brasil \\ ${ }^{b}$ Centro de Engenharias e Ciências Exatas, Universidade Estadual do Oeste do Paraná, 85903-000 Toledo - PR, Brasil
}

Recebido em 28/11/2019; aceito em 18/02/2020; publicado na web em 14/04/2020

\begin{abstract}
PHOTODYNAMIC THERAPY IN ELECTROSPINNING: REVIEW OF TECHNIQUES AND APPLICATIONS. Electrospinning is a strand of nanoscience for the production of fibers in nano and micrometric scales and when combined with other techniques it becomes a powerful tool for application in various branches of science. A promising combination of electrospinning is photodynamic therapy (PDT) and photodynamic inactivation of microorganisms (PDI) for the manufacture of fibers with photoactive characteristics that can be used with great ease in the medical field. This systematic review reports technical information, preparation and characterization of nano and microfibers obtained by the electrospinning technique with applicability in PDT/PDI.
\end{abstract}

Keywords: functionalized tissue, photosensitive material, nanotechnology.

\section{INTRODUÇÃO}

O ano de 1959 com o prêmio Nobel recebido por Richard Feyman, a comunidade científica despertou para inserção da nanotecnologia no cotidiano da sociedade. Em 1974 o cientista Norio Taniguchi utilizou pela primeira vez o termo "nanotecnologia" em uma publicação científica, enumerando as propriedades materiais que a técnica poderia fornecer. ${ }^{1}$ Nanotecnologia é a manipulação, controle e entendimento da matéria em dimensões inferiores a 100 nanômetros, unindo consigo a engenharia, ciência e tecnologia para a formulação de unidades estruturais de grãos, partículas, fibras e outros materiais, o que torna possível a preparação de nanomaterias, nanodispositivos e nanosistemas. ${ }^{2,3}$ Nessa vertente da nanotecnologia aparece a eletrofiação (ES), técnica capaz de formar de maneira direta fibras poliméricas com diâmetros inferiores a $200 \mathrm{~nm}$. Os materiais nanofibrosos devido a elevada superfície e funcionalidades têm sido utilizados para os mais variados fins, compreendendo vários ramos da ciência e da indústria. $\mathrm{O}$ termo funcionalização se caracteriza pela incorporação de funções químicas ou biológicas por meio da manipulação desses materiais, sendo elas de forma controlada e pré-determinada. ${ }^{4}$

Outra área crescente no campo de inovação é a chamada Terapia Fotodinâmica (TFD). Este tratamento médico se destaca como alternativa na cura de pacientes através de uma técnica, a princípio destrutiva, pois se destrói tecidos indesejáveis. Ao destruir o tecido indesejável tem-se sua eliminação, levando a cura. Esta pode ser aplicada em várias doenças tais como câncer, ${ }^{5}$ degeneração macular da retina ${ }^{6}$ e Leishmaniose cutânea. ${ }^{7} \mathrm{O}$ diferencial da TFD está na utilização da luz visível em conjunto com um medicamento fotossensível na presença de oxigênio, gerando espécies altamente reativas que in situ causam a morte de células. Particularmente destacam-se células com crescimento anormalmente rápido. Neste sentido além de tumores, a TFD permite combater e inativar bactérias, fungos, protozoários e outros tipos de microrganismos, variante conhecida como Inativação Fotodinâmica de Microrganismos (IFDMO), ${ }^{8,9}$ sendo que muitos destes são responsáveis pelo agravamento de feridas.

Este trabalho objetiva revisar as produções científicas que englobam a eletrofiação e as técnicas fotodinâmicas, a utilização de

*e-mail: nhioka@uem.br, dcdragunski@gmail.com agentes fotoativos como adsorvente ou funcionalizadores em materiais eletrofiados e suas aplicações na medicina.

\section{PROCESSO DE ELETROFIAÇÃO}

A técnica de eletrofiação de polímeros com a intenção de produzir fibras poliméricas em escala nano ou micrométrica por meio de forças eletrostáticas, atualmente é uma metodologia mundialmente reconhecida, porém passou por várias variantes históricas, conforme Figura 1, até chegar ao seu estopim de publicações. ${ }^{10}$ A primeira descrição de atração eletrostática por líquidos foi realizada em 1600 por William Gilbert. Porém, apenas em 1900 foram obtidos os primeiros dispositivos capazes de pulverizar líquidos por aplicação de carga elétrica, realização essa de Cooley e Morton. Posteriormente, em 1934 o processo foi patenteado, porém sem utilização comercial. Entre 1964 e 1969, Geoffrey Taylor estudou e publicou o modelo matemático relacionado a estabilidade eletrohidrodinâmica, processo esse que governa toda a técnica. A visibilidade acadêmica deu-se em 1990, iniciada pelo grupo de Reneker que popularizou a terminologia eletrofiação. A partir dos anos 2000, ocorreu um crescimento exponencial de publicações devido à obtenção de materiais altamente funcionais..$^{11-13}$

As aplicações para as nanofibras se estendem em vários ramos distintos, tais como medicina, engenharia de tecidos, filtração, energia e eletrônica, sensores e roupas protetivas. ${ }^{14}$ Sua utilização na medicina já relatada abrange a entrega de fármacos,${ }^{15}$ curativos ${ }^{16} \mathrm{e}$ dispositivos hemostáticos. ${ }^{17}$ Quando citada a engenharia de tecidos, as mesmas podem ser como vasos sanguíneos ${ }^{18}$ e regeneração de nervos, ${ }^{19} \mathrm{sca}$ ffold 3D para a regeneração de tecidos, ${ }^{18}$ membrana porosa para a regeneração da pele. ${ }^{20}$ Como meio filtrante ${ }^{21}$ são capazes de barrar líquidos, gases e moléculas. Para área de energia e eletrônica, podem ser tomados como exemplos células fotovoltaicas, ${ }^{22}$ baterias ${ }^{23}$ e dispositivos de LDC. ${ }^{24}$ Sensores eletroquímicos, ${ }^{25}$ piezelétricos ${ }^{26}$ e de fluorescência óptica ${ }^{27}$ podem ser construídos a partir de nanofibras, como também roupas protetivas ${ }^{28}$ antigases bioquímicos e capturadores de aerossol.

Dentre os ramos que mais geram publicações, pode ser destacada a catálise. O sucesso da eletrofiação na catálise é dada pela razão do comprimento-diâmetro alto das estruturas formadas. Além disso, a grande área superficial e a estabilidade catalítica fornecidas mesmo 


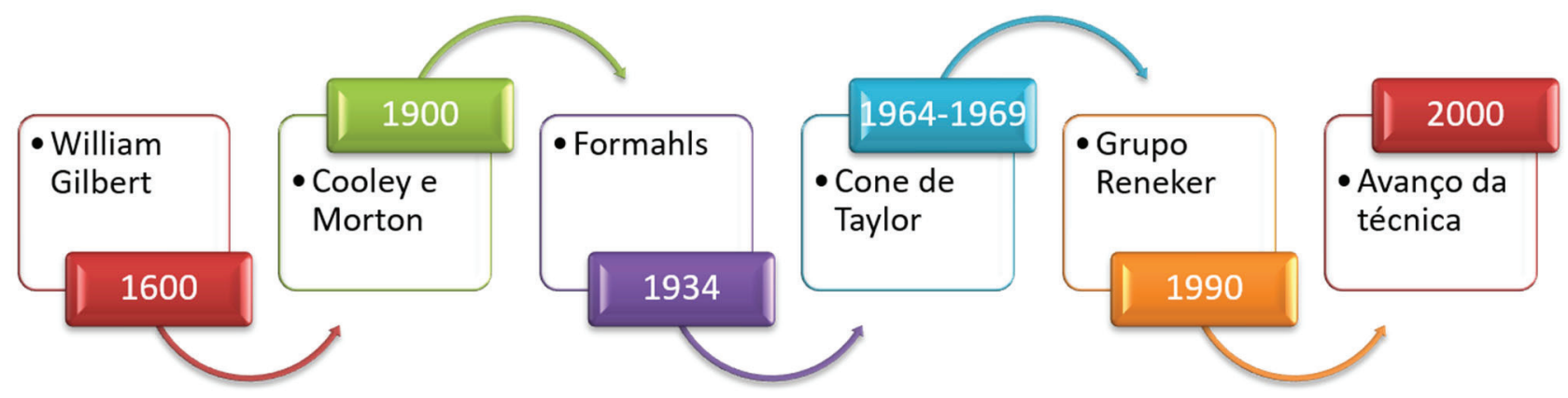

Figura 1. Cronologia histórica da eletrofiação

com a incorporação de partículas metálicas, semicondutoras e outras ao material eletrofiado, são pontos importantes para a catálise. ${ }^{29} \mathrm{O}$ segundo ramo mais procurado é a engenharia de tecidos, isso se deve a estrutura porosa do material eletrofiado, que é adequada para ser utilizado como uma matriz extracelular artificial. Também possui uma relação superfície/volume alta o que é capaz de melhorar a adesão celular e no transporte de nutrientes. ${ }^{30}$ Silva et al. (2019) ${ }^{31}$ realizam testes in vivo em ratos de material eletrofiado a partir de poli( $\varepsilon$-caprolactona) (PCL) e copolímero F-108 juntamente com curcumina, um fármaco com características anti-inflamatórias, microbiana e antioxidante, para verificar a resposta de cicatrização de feridas. Os autores verificaram que o material foi capaz de auxiliar em todos os períodos a cicatrização das feridas (reepitelização, proliferação e revascularização), além de aumentar a biodisponibilidade do fármaco e a sua entrega. Por fim, os autores acreditam que o material pode ser credenciado como um curativo promissor aplicável na engenharia de tecidos.

O sistema usado em escala laboratorial desta técnica consiste em três componentes principais: fonte de alta tensão, capilar (agulha metálica) e coletor metálico, além disso, pode ser destacada a bomba de injeção. A corrente contínua de alta tensão é fornecida pela agulha (que está em contato com a seringa contendo solução polimérica a ser fiada), enquanto que o coletor é aterrado. Quando ocorre a formação da gota na ponta do capilar, na presença da alta tensão fornecida a agulha, tem-se a formação do cone de Taylor (que governa todo o processo). O cone de Taylor é formado quando as forças eletrostáticas são superiores a tensão superficial da solução e que devido ao campo elétrico formado, propicia o estiramento da gota em forma de fibra e sua deposição como não tecidos e de maneira aleatória (Figura 2). Da ponta do capilar até o alvo coletor todo o solvente é evaporado, restando apenas as fibras poliméricas. ${ }^{32-34}$

A morfologia das fibras depende de vários parâmetros, tais como: concentração, viscosidade, condutividade, taxa de vazão, distância do alvo coletor, volatilidade do solvente, tensão aplicada e fatores ambientais. Geralmente, esses parâmetros são interconectados e variam de acordo com o polímero utilizado. ${ }^{35} \mathrm{~A}$ viscosidade e a concentração estão relacionadas com a capacidade de fiação das soluções, onde concentrações muito elevadas de polímeros dificultam a formação das fibras. O entupimento do capilar devido à alta viscosidade também prejudica estiramento e jato uniforme das fibras ao coletor. Como a eletrofiação é dependente das interações eletrostáticas, a solução deve apresentar certa condutividade. ${ }^{36} \mathrm{~A}$ volatilidade do solvente também é um fator importante, visto que o mesmo deve desaparecer durante o trânsito do jato sólido de nanofibras, assim, quanto maior a volatilidade do solvente, maior a porosidade do material obtido. Outro aspecto significativo são os fatores ambientais como temperatura e umidade. A faixa de umidade ideal para eletrofiação é de $30 \%$. A taxa de vazão é empregada para manter a produção contínua das fibras, sendo vazões menores mais desejáveis para evitar "beads". A separação da ponta do capilar até o alvo coletor deve ser ajustada de maneira que ocorra toda a secagem do solvente. ${ }^{37}$

O polímero a ser usado pode proporcionar uma vasta gama de propriedades ao tecido eletrofiado, entre elas resistência, peso, porosidade e em alguns casos até uma superfície funcionalizada pode ser obtida. Para o processo de eletrofiação já foram relatados mais

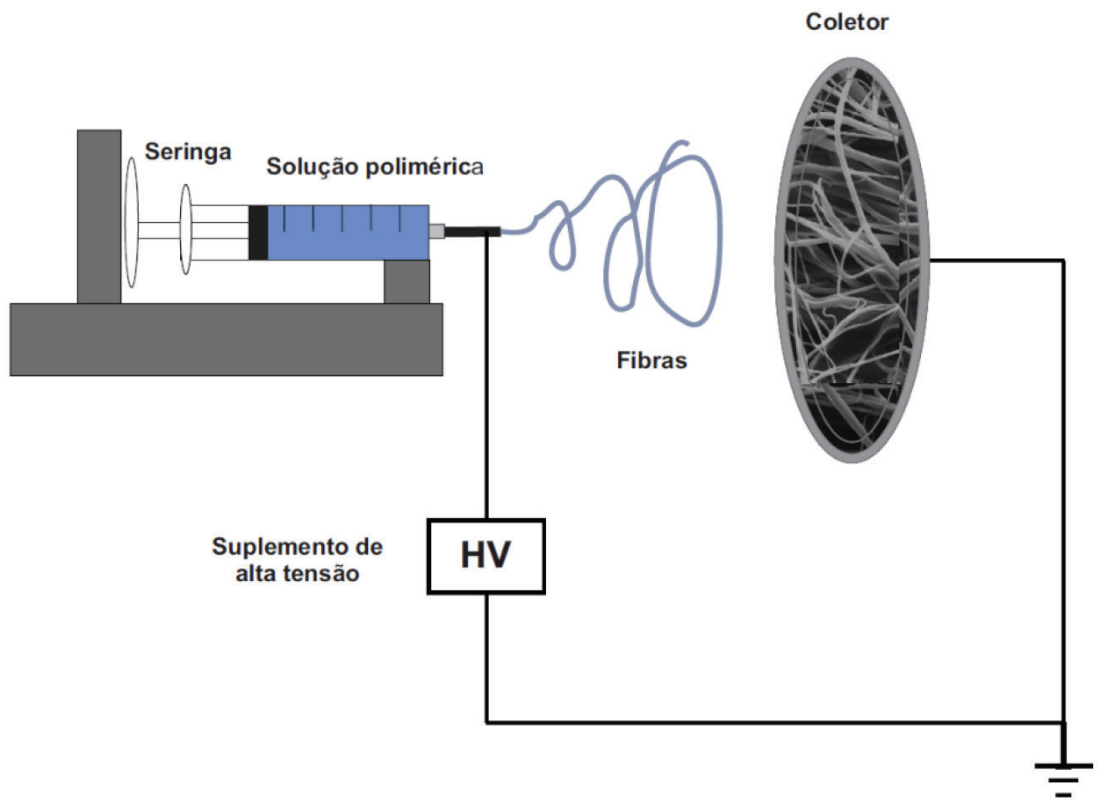

Figura 2. Arranjo laboratorial para sistema de eletrofiação 
de 200 polímeros com potencial para serem eletrofiados, sendo esses sintéticos, naturais ou mistos. ${ }^{38}$ Polímeros naturais como gelatina, colágeno, elastina e outros, são bastante empregados em aplicações biomédicas devido a apresentar uma melhor biocompatibilidade e baixa imunogenicidade (capacidade de causar resposta imunológica). Polímeros sintéticos apresentam maiores vantagens em relação aos naturais, uma vez que podem ser adaptados a título de obter uma ampla gama de propriedades, tais como propriedades mecânicas e taxa de degradação. Alguns polímeros sintéticos que podem ser destacados são poli(ácido láctico) (PLA), poliuretano (Pu) e PCL. ${ }^{39}$

\section{Funcionalização de nanofibras eletrofiadas}

A modificação superficial de polímeros é necessária para aplicação do mesmo em campos amplos de utilização na sociedade humana, sendo um tópico antigo de estudo. Entretanto, polímeros que apresentam alta resistência mecânica e são quimicamente estáveis, geralmente, propiciam uma superfície inerte para fins químicos e/ou biológicos. Já o uso de polímeros que possuem superfícies ativas, porém com propriedades mecânicas baixas, levam a impossibilidade uma aplicação mais efetiva. Devida a essa dubiedade, a modificação da superfície polimérica sem que ocorra a alteração das propriedades intrínsecas do polímero possui uma grande e clássica pesquisa. Como técnicas de modificação superficial, pode-se destacar revestimento físico/mistura, copolimerização de enxertos e tratamentos químicos. ${ }^{36}$

O revestimento físico ou a mistura de agentes bioativos é a forma mais simples de modificação superficial. Como o nome mesmo diz, nessa técnica as moléculas funcionais são misturadas à solução polimérica ou recobrem a superfície por meio de adsorção. ${ }^{36} \mathrm{Em}$ 2016, Ning et al. reportaram um trabalho no qual revestiram fibras de fluoreto de polivinilideno (PVDF) com nanopartículas de prata (AgNPs) para aplicação fotocatalítica, comparando o método de mistura e de revestimento, onde ambos foram testados como agente degradante de laranja de metila (MO). Os resultados indicaram que o método de revestimento físico foi mais satisfatório para a degradação do que o método de mistura de $\mathrm{AgNPs} .{ }^{40}$ Para entrega de fármacos, Canbolat et $a l .{ }^{41}$ relataram a eletrofiação de uma solução contendo PCL e o medicamento de referência naproxeno (NAP), muito utilizado no combate de dor e febre. Um estudo adicional também verificou a complexação do fármaco em uma nanoestrutura capaz de melhorar sua estabilidade e concentração. Como metodologia foi utilizada a betaciclodextrina (BD) como formador do complexo de inclusão (NAP-BD-IC), capaz de fornecer maior estabilidade ao fármaco. Como meio de funcionalização foi utilizado método de mistura simples. Como parâmetro de comparação, também foram eletrofiadas a mistura PCL/NAP para averiguar o perfil de liberação, onde pode ser observado que PCL/NAP-BD-IC possui melhor caráter de sistema liberador devido a melhor solubilidade do medicamento pela BD e proporcionando um ambiente consistente para o fármaco.

A modificação via copolimerização enxerto utilizam radicais ou grupos radicais como meio de modificação superficial, onde esses grupos ativantes são introduzidos na superfície por métodos de irradiação (UV, raios- $\gamma$ e etc.), tratamento com plasma, oxidação de ozônio ou peróxido. ${ }^{42}$ Como vantagens têm-se a capacidade de inserção de grupos de alta densidade de carga e volume, bem como monômeros diferentes e entre outros. ${ }^{36}$ Surucu et al ${ }^{43}$ investigaram a modificação que jatos de plasma poderiam ocasionar em mantas eletrofiadas a partir da blenda PCL/Quitosana/PCL na fixação e crescimento celular de fibroblastos humanos. Para isso, foram utilizadas misturas de gases $\mathrm{Ar}, \mathrm{Ar}+\mathrm{O}_{2}, \mathrm{Ar}+\mathrm{O}_{2}+\mathrm{N}_{2}$ e as modificações do plasma de ar seco por pressão atmosférica e os jatos de plasma Diener (PlasmaBeam). Os autores notaram que as mantas eletrofiadas modificadas com plasma foram capazes de aumentar de maneira expressiva a hidrofilicidade, funcionalidade de oxigênio e a topografia estrutural, acarretando de maneira positiva a viabilidade celular e a propagação dentro das mantas. Thielke et al ${ }^{44}$ utilizou o método de irradiação UV como auxílio para reticulação de fibras de polibutadieno (BR) com o intuito de obter fibras mais estáveis e com propriedades mecânicas, sem que ocorresse a união das mesmas, uma vez que o polímero em questão possui baixa temperatura de transição vítrea $\left(\mathrm{T}_{\mathrm{g}}\right)$. Além de promover a reticulação dentro das fibras, a luz UV foi capaz de fornecer ligações duplas na superfície da fibra, permitindo aos autores a inserção de grupamentos tiol-eno que, em contrapartida, forneceu uma superfície hidrofílica.

Polímeros que possuem grupamentos funcionais carboxílicos, amino, éster e outros, podem ter sua superfície modificada quimicamente pela inserção de espécies químicas, fornecendo características superficiais químicas e físicas melhoradas. As reações nesse processo podem ser realizadas em locais de vulnerabilidade a ataques eletrofílicos e nucleofílicos. ${ }^{36} \mathrm{~A}$ fim de melhorar propriedades mecânicas tais como resistência e hidrofilicidade de membranas de nanofibras eletrofiadas para utilização em filtração de água, Huang et al. ${ }^{45}$ realizaram uma modificação química com polidopamina (PDA) em membranas de poliacrilonitrila (PAN) e polissulfona (PSu). Como resultado, os autores constataram que a modificação propiciou as membranas um aumento em até $300 \%$ na resistência de tração, conseguindo manter a elasticidade, estrutura porosa e permeabilidade significativa; além disso, a hidrofilicidade não foi alterada podendo esse material ser aplicado além do campo de filtração.

\section{TERAPIA FOTODINÂMICA}

A luz como forma de tratamento junto com plantas já era conhecida no antigo Egito. Esta forma de aplicação "intuitiva" foi utilizada até a descoberta em 1900 por Raab do efeito fotodinâmico do alaranjado de acridina sobre o protozoário Paramecium. ${ }^{46}$ Após este evento iniciou-se os estudos de inativação fotodinâmica utilizando fotossensibilizadores naturais e/ou sintéticos, culminando na forma de tratamento conhecida como Terapia Fotodinâmica (TFD), com aplicação clínica utilizando-se de derivados de porfirinas a partir dos anos 50. As pesquisas com corantes fotoativos, chamados de fotossensibilizadores (FS), teve como objetivo aprimorar as características foto-físicas para atender esta nova forma de tratamento e as três gerações de FS existentes demonstram essa evolução. ${ }^{47-49}$ Os FS compreendem diversas classes de corantes, como por exemplo, porfirinas, clorinas, ftalocianinas, xantenos, fenotiazinas, dentre as quais as porfirinas e seus derivados compõem os principais medicamentos aprovados para aplicação clínica em TFD (Photofrin, Foscan, Levulan Kerastic, ALA, Visudyne). ${ }^{50-52}$ A TFD tem como base três componentes: luz, fármaco fotossensível e oxigênio, caracterizada por ser altamente seletiva, pois a morte celular ocorre apenas na região onde o par, luz e composto, está presente sendo que o fármaco pode ser direcionado para o tecido específico. ${ }^{53,54}$

A reação fotoquímica para a formação de espécies reativas, uma condição primordial para a TFD, é dada pela iluminação dos cromóforos em um comprimento de onda no qual ela é capaz de excitar o FS a um estado de curta duração, designado de estado singlete excitado, representado como ${ }^{1} \mathrm{FS} *$. Ao atingir tal estado, o cromóforo pode passar por vários estados e, para a TFD, o cruzamento intersistema (ICS) é o importante. Este corresponde à mudança na multiplicidade de spin, levando ${ }^{1} \mathrm{FS}^{*}$ a um estado de energia pouco menor, o estado triplete $\left({ }^{3} \mathrm{FS} *\right)$. Quando o estado triplete é atingido, a energia pode ser perdida como fóton fosforescente ou através de interação com moléculas abundantes no meio, como exemplo o oxigênio molecular, e assim formar espécies altamente reativas. A formação de espécies reativas segue dois tipos de mecanismo: transferência de energia (1) 
com geração de espécies reativas de oxigênio (EROS) ou transferência de elétrons (2), podendo ambos ocorrerem simultaneamente e têm como dependência o tipo de FS, concentração de substrato no meio e oxigênio disponível. A reação do tipo 2 é de maior interesse para a TFD sendo este o mecanismo mais simples e mais comum. ${ }^{53-56}$ Uma representação esquemática para processos fotodinâmicos é mostrada na Figura 3.

A aplicação do fármaco fotoativo em pacientes deve ser acompanhada de uma dose de luz, isto é uma quantidade de fótons necessários, que serão absorvidos pelas moléculas de FS, e isto envolve o tempo de iluminação e a distância entre a fonte de luz e o tecido iluminado (dosimétrico). ${ }^{57}$ Estudos relacionados a TFD vem sido amplamente reportados, uma vez que esta modalidade clínica apresenta mínimos efeitos colaterais, principalmente quando comparados a outras modalidades clínicas tais como radioterapia e quimioterapia. ${ }^{58}$ Sua aplicação estende-se ainda a inativação de microrganismos e esterilização de ambientes uma vez que seus principais componentes ativos são agentes citotóxicos, sendo eles oxigênio singleto e EROS. Adicionalmente, não há o desenvolvimento de mecanismos de resistências em bactérias, fungos, parasitas e vírus, ou seja, seu campo de aplicação é mais amplo e atrativo do que os medicamentos disponíveis. ${ }^{59}$ Um exemplo é a utilização de TFD para o tratamento de doenças negligenciadas na América Latina, tais como Doença de Chagas (Trypanosoma cruzi) e leishmaniose cutânea (Leishmania amazonensis e Leishmania guyanensis), sendo o Brasil um dos países que possuem centros de tratamentos especializados em TFD..$^{60,61}$ Nesi-Reis et $a l .{ }^{62}$ estudaram a atividade anti-inflamatória de três fotossensibilizadores distintos, ftalocianina de alumínio ( $\mathrm{FtAlCl}$ ), ftalocianina de zinco (FtZn) e hidróxido de alumínio (FtAlOH), frente a promastigotas (forma flagelada) e amastigotas de L. amazonenses na presença e ausência de iluminação. Os autores observaram que para a $\mathrm{FtAlCl}$ e $\mathrm{FtAlOH}$ a presença de luz causou um efeito antileishimania sem que ocorra danos aos macrófagos e eritrócitos, células essas responsáveis pela fagocitose. Já a FtZn não foi capaz de inibir promastigotas de L. amazonenses. Os autores destacam a partir dos resultados a possibilidade do uso de FtAlCl e FtAlOH para tratamento de Leishmaniose cutânea.

As perspectivas futuras da TFD estão relacionadas ao seu estabelecimento como forma de tratamento, com protocolos terapêuticos definidos, e a parte de diagnóstico por imagem de fluorescência seguido do tratamento que pode ocorrer de forma simultânea (teranóstica) com aplicação de um único FS.

\section{INATIVAÇÃO FOTODINÂMICA}

A Inativação Fotodinâmica de Microrganismos (IFDMO, "PDI, Photodynamic Inactivation") ${ }^{63}$ ou Quimioterapia Fotodinâmica Antimicrobiana ("PACT, Photodynamic Antimicrobial Chemotherapy") ${ }^{64}$ é uma alternativa não seletiva para tratamento de microrganismos que podem se tornar resistentes. Esta técnica tem o mesmo princípio da TFD, onde a conversão do oxigênio molecular em oxigênio singlete e/ou EROS causam a morte dos microrganismos depois de um tratamento com um FS apropriado e luz visível. É uma modalidade de tratamento para infecções bacterianas, virais, protozoáricas e fúngicas, onde o oxigênio singlete é o principal agente citotóxico aos agentes microbianos. ${ }^{65,66}$

Fotossensibilizadores agem via produção de oxigênio singlete, não importando se a cepa de microrganismo é resistente à uma ou mais classes de antimicrobianos. A partir da década de 90 a Terapia Fotodinâmica Antimicrobiana passou a ser uma alternativa no tratamento contra bactérias resistentes à ação de antibióticos comumente utilizados. ${ }^{67}$ Uma diversidade de fotossensibilizadores, pertencentes a diferentes grupos de compostos, tais como: xantenos halogenados como exemplo a rosa de bengala, ou fenotiazínicos como azul de toluidina e azul de metileno, acridinas e conjugados de clorina são utilizados na inativação de microrganismos. ${ }^{56,66}$ Além destas, diferentes rotas sintéticas fornecem uma vasta gama de compostos com grande potencial para aplicação em IFDMO.

De Moraes et al. ${ }^{68}$ estudaram a inativação fotodinâmica in vitro de Trypanosoma cruzi utilizando como fotossensibilizador hipericina estruturado em nanocarreadores micelares. Os autores verificaram que em concentrações micromolares todas as formulações estudadas se mostraram viáveis para a inativação do protozoário da Doença de Chagas. Os resultados indicam que a formulação pode ser empregada como medicamento quimioterapêutico. Da Silva Junior et al., ${ }^{69}$ utilizando como fotossensibilizador Safranina-O em nanocarriadores micelares, avaliaram a inativação in vitro e in vivo de Staphylococcus aureus, Escherichia coli, Corynebacterium bovis e Streptococcus

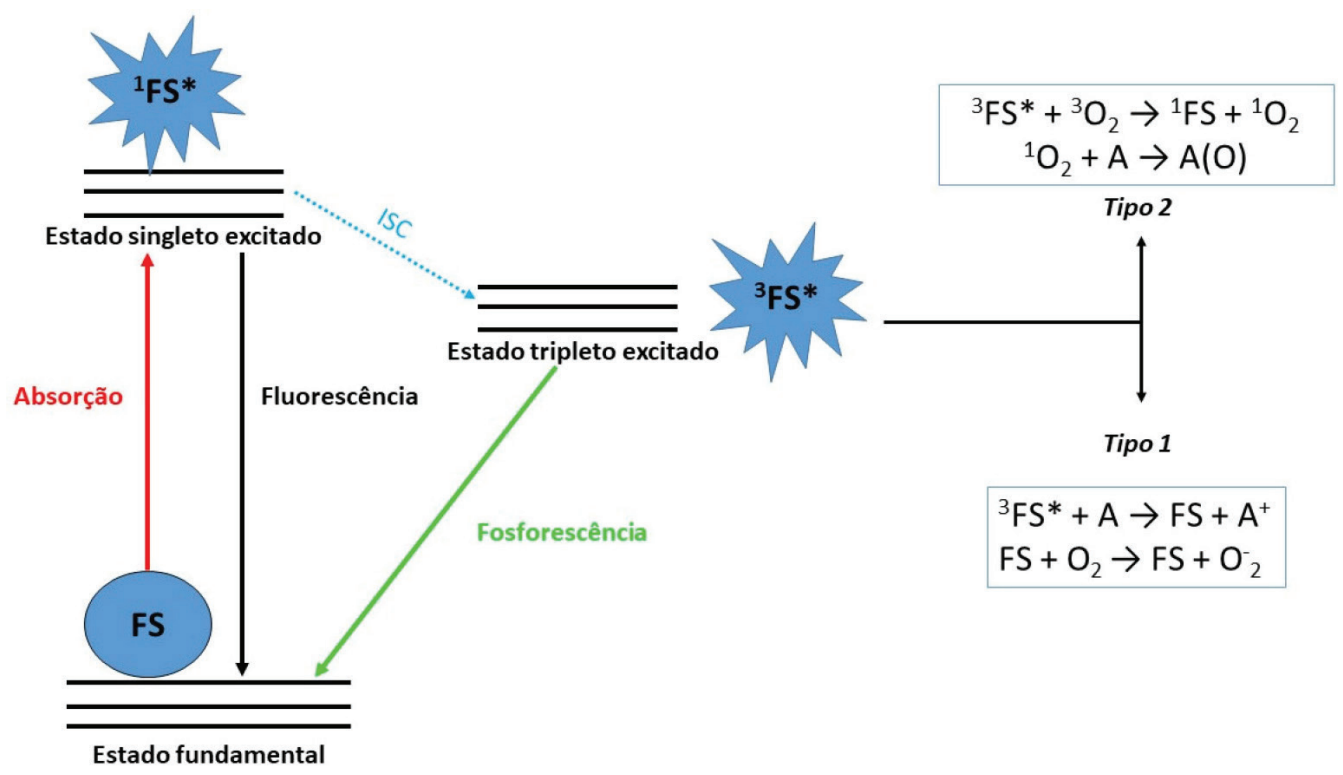

Figura 3. Diagrama de Jablonski para processos fotodinâmicos que levam a formação de espécies reativas de oxigênio. Abreviaturas: FS: fotossensbilizador no estado fundamental; ${ }^{l} \mathrm{FS}$ : fotossensibilizador no estado singlete excitado; ${ }^{3} \mathrm{FS}$ : fotossensbilizador no estado triplete; ISC: cruzamento intersistema; A: substrato orgânico 
agalactiae, patógenos causadores de mastite bovina. Os resultados in vitro demonstraram que os sistemas foram capazes de inativar todos os microrganismos estudados. Quando avaliadas in vivo, em vacas leiteiras, as formulações destacaram-se como um método preventivo a mastite bovina, podendo ser combinada com outros tratamentos sem que ocorra alteração na lactação das vacas.

\section{UNIÃO DA ELETROFIAÇÃO E FOTOSSENSIBILIZADORES PARA TFD E IFDMO}

Em 2007, Mosinger et al. ${ }^{70}$ publicou o primeiro trabalho, esse em forma de comunicação, relatando os resultados obtidos com a união da eletrofiação em conjunto com fotossensibilizadores. Nesse trabalho, os autores avaliaram dois tipos de inserção de fármacos fotoativos a solução de poliuretana (PU) a ser eletrofiada. A primeira formulação partiu de uma solução de PU, brometo de tetraetilamônio (TEBA) e tetrafenilporfirina (TPP). A segunda formulação além dos componentes já citados, também teve a adição de dodecil sulfato de sódio (SDS), um surfactante aniônico que conferia a solução caráter mais hidrofílico. O diâmetro médio das fibras foi de $460 \mathrm{~nm}$, para ambas as formulações. Além disso, os autores relataram a produção de oxigênio singlete com a aplicação de uma irradiação no comprimento de onda de $650 \mathrm{~nm}$, promovendo um efeito bactericida frente a bactérias Escherichia coli.

Posteriormente, em 2009, Mosinger et al.$^{71}$ deram continuidade a suas pesquisas de nanotecidos embebecidos com FS, usando desta vez outro aparato para eletrofiação e novo FS, fornecendo também uma comparação com a TPP relatada anteriormente. Para esse trabalho, as nanofibras de PU foram dopadas com tetrafenilporfirina de zinco (ZnTPP) e/ou ftalocianina de zinco (FtZn). As três formulações testadas continham como base PU e surfactante Slovasol, a diferenciação se dava na inserção do fotossensibilizador, onde foram formadas fibras com FtZn e ZnTPP em separados e por fim, a mistura de FtZn e ZnTPP. Por técnicas fluorimétricas os autores verificaram o estado monomérico dos FS, com pequeno desvio batocrômico indicado pela interação do FS com os grupamentos do polímero. Ainda foi constatada a eficiência na formação de ${ }^{1} \mathrm{O}_{2}$ com tempo de $15 \mu \mathrm{s}$ em ar atmosférico, o qual para as fibras com as misturas dos FS o tempo de vida foi mais proeminente. Além disso, o material comprovou a superfície bactericida e o poder de degradação de substratos de origem inorgânica e orgânica. Outro resultado obtido foi a menor fotoestabilidade dos FS (ZnTPP e FtZn) comparados com a TPP de base livre, ou seja, TPP sem a complexação com qualquer metal.

Jesenská et al., ${ }^{72}$ em 2011, eletrofiou diferentes soluções poliméricas utilizando como FS a TPP. Uma primeira solução continha poliuretana de Larithane $^{\mathrm{TM}}$ (LPU) juntamente com TEAB e TPP. A segunda solução usava poliestireno (PS) com TEAB e TPP. A terceira solução continha PCL com TPP e por fim, a última solução de poliamida 6 (PA6) e TPP. Os diâmetros médios da nanofibras foram de $250 \mathrm{~nm}$ para LPU, $300 \mathrm{~nm}$ para PS, $80 \mathrm{~nm}$ para PCL e $150 \mathrm{~nm}$ para PA6. Os resultados demonstraram a formação de ${ }^{1} \mathrm{O}_{2}$ por todos os materiais em ordem crescente PS $\geq$ LPU > PCL >> PA6, além de estado monomérico para os fotossensibilizadores. Os estudos de permeabilidade indicam uma alta permeabilidade de $\mathrm{O}_{2}$ para PS e LPU o que corroboraram com a maior formação de espécies reativas do que para PCL e PA6. Quando observados os ensaios in vivo, os tecidos de LPU, PS e PCL apresentaram efeito bactericida prolongado, mesmo no escuro após a irradiação, inibindo o crescimento das bactérias. Para PA6 o efeito bactericida foi baixo devida a baixa formação de ${ }^{1} \mathrm{O}_{2}$ relatada anteriormente. Os autores indicam a utilização do material para aplicações médicas.

A partir de 2012, surgiram mais trabalhos relatando a eletrofiação e FS com fins fotodinâmicos. Yoo et al..$^{73}$ propuseram a formulação de espaçadores oriundos de nanotecidos embutidos com o FS ácido 5-aminolevulínico (ALA) para a necrose de Colangiocarcinoma (CC), um tipo maligno de câncer proliferado em células epiteliais de vias biliares. Para isso, foi preparada uma solução de álcool polivinílico (PVA) com ALA. O material produzido foi utilizado como revestimento de espaçadores de metal e foram submetidos à comprovação de efeitos de TFD em ensaio in vitro usando CC. O diâmetro médio das fibras foi de $1000 \mathrm{~nm}$. Quando comparadas com ALA livre, as fibras foram capazes de reduzir a toxidade de ALA no escuro. Também em teste in vitro realizado com tempo de contato de 24 horas do material com as células, a necrose (morte patológica) foi similar à da solução de ALA, porém foi capaz de gerar apoptose um pouco superior. Já a apoptose (morte celular programada) foi mais expressiva para as fibras contendo o FS. Diante disso, os autores externam que o nanomaterial é promissor para o tratamento paliativo de CC.

Ainda em 2012, Arenbergerova et al. ${ }^{74}$ desenvolveram tecidos nanofibrosos ativados por luz, com intuito de tratamento terapêutico para úlceras em membros inferiores (pernas). Para isso foram formuladas nanofibras de TPU dopadas com TPP e brometo de tetraetilamônio, usando como sistema de eletrofiação o Nanospider ${ }^{\mathrm{TM}}$. Foram realizados ensaios in vitro contra microrganismos Staphylococcus aureus, Pseudomonas aeruginosa e E. coli e ensaio in vivo utilizando 162 pacientes com feridas crônicas. $\mathrm{O}$ estudo indicou que para os filmes dopados com TPP com iluminação máxima de 30 minutos houve um efeito máximo de anti-crescimento para os três grupos de microrganismos, não sendo evidenciado o crescimento de colônias. Em contrapartida, para os filmes não dopados e não iluminados, foi observado o crescimento abrupto dos microrganismos. Nos ensaios in vivo, os pacientes tratados com nanomaterial dopado e iluminado o efeito de cicatrização das úlceras foi muito superior aos que tiveram o material deixado no escuro. $\mathrm{O}$ grupo que recebeu material e iluminação tiveram crescimento epitelial saudável e o diâmetro de suas feridas reduzidas drasticamente após 42 dias de tratamento. Estes estudos abriram um amplo campo de possibilidades de materiais eletrofiados dopados a serem empregados na área médica como auxílio à cicatrização de feridas e/ou no pós-operatório.

Lhotáková et al., ${ }^{75}$ ainda em 2012, averiguaram a capacidade virucida de nanofibras de PCL e TPU (poliuretana Tecophilic ${ }^{\mathrm{TM}}$ ) encapsuladas com TPP frente à poliomavírus não-envelopados e baculovírus envelopados. O primeiro material foi composto de TPU, TEAB e TPP e o segundo apenas de PCL e TPP. O diâmetro médio obtido para TPU $(89 \pm 22 \mathrm{~nm})$ foi muito inferior aos de PCL $(204 \pm 106 \mathrm{~nm})$, com espessuras $93 \mu \mathrm{m}$ e $320 \mu \mathrm{m}$ respectivamente. A certificação da porfirina nos tecidos, bem como a geração de ${ }^{1} \mathrm{O}_{2}$ foram confirmadas por espectroscopia UV/Vis e microscopia de fluorescência confocal. A fluorescência demonstrou fase monomérica para o FS empregado nas fibras, além de um tempo de vida no estado triplete de $18 \pm 2 \mu \mathrm{s}$ para TPU e $10 \pm 4 \mu$ s para PCL. Os materiais iluminados por cerca de 30 minutos contendo FS foram capazes de inibir os vírus estudados, tornando-os não infecciosos. Ainda, o mesmo teste in vitro foi realizado um ano após o preparo do material e os mesmos resultados foram obtidos. Os autores ressaltam que o material não permite a difusão de $\mathrm{O}_{2}$ internamente devido ao diâmetro pequeno das fibras, o que dá uma característica apenas de superfície bactericida, mas ainda assim indicam um forte potencial desses materiais para possíveis aplicações biomédicas.

No ano de 2013, Masilela et al. ${ }^{76}$ avaliaram a inativação de $S$. aureus por meio de diferentes FS oriundos de ftalocianinas $(\mathrm{Ft})$ simetricamente substituídas, onde esses foram suportados em nanofibras de poliestireno (PS). As Ft escolhidas foram a tris $\{9(10), 16(17), 23(24)-(4-f e n o x i)-2-(4-$ -cistenil)ftalocianina zinco (FtMcsZn), ftalocianina de monofenoxi-carboxi-zinco (FtMfcZn), di-hidroxi de tris\{9(10), 16(17), 
23(24)-4-(2-dietilaminoetanotiol)-2-(4-carboxiftalonitrila) ftalocianinato $\}$ germânio (IV) $\left(\mathrm{FtMtGe}(\mathrm{OH})_{2}\right)$, óxido de tris $\{9(10)$, 16(17), 23(24)-4-(2-dietilaminoetanotiol)-2-(4-carboxiftalonitrilo)ftalocianinato $\}$ titânio (IV) (FtMcOTi), tris $\{9(10), 16(17)$, 23(24)-4-(2-dietilaminoetanotiol)-acetato de 2-(4-carboxiftalonitrila) ftalocianinato estanho (IV) (FtMtSn(ac) $)_{2}$. A solução de trabalho consistia em PS com a adição de FtMcsZn, FtMfcZn, FtMtGe $(\mathrm{OH})_{2}$, FtMcOTi, FtMtSn(ac) $)_{2}$ e FtZn, em separado. Os autores atestaram como positiva a eletrofiação dos complexos de ftalocianinas na matriz polimérica, bem como diâmetros médios variando entre $240 \pm 45 \mathrm{~nm}$ e $390 \pm 30 \mathrm{~nm}$. As Ft que continham grupamentos capazes de formar ligações de enxofre com o polímero geram um desvio hipsocrômico em sua absorção. Já quando avaliada a formação de ${ }^{1} \mathrm{O}_{2}$, para os materiais eletrofiados este foi menor do que em solução devido a agregação nas concentrações propostas. Assim como para Mosinger et al. ${ }^{71}$ não foi possível averiguar a atividade fotodinâmica para $\mathrm{ZnFt}$ e nem para ZnTPP devida a baixa produção de espécies reativas, assim atestado pelos autores. Para as demais Ft foram notadas inativação em torno e sobre as fibras modificadas para o microrganismo contra $S$. aureus, o mesmo não foi notado para o padrão contendo apenas polímero e escuro, indicando projeções para aplicações práticas futuras.

Wu et $a l .{ }^{77}$ (2013) estudaram a eletrofiação de poli(L-ácido láctico) (PLLA) com a inserção de Purpurin-18 (Pur-18) contra células cancerígenas humanas de origem hepática e de esôfago. A solução a ser fiada era composta de PLLA e Pur-18, obtendo um diâmetro médio de $345 \mathrm{~nm}$. Por meio de microscopia fluorescente e espectroscopia no infravermelho foi denotada a distribuição uniforme da Pur-18 ao longo das fibras e uma boa compatibilidade com a matriz polimérica. Quando verificados em testes in vitro, a adesão celular e espalhamento pela superfície do material foi observada, o que denota uma biocompatibilidade e toxidade imperceptível no escuro. Já quando verificada a ação fotodinâmica após a irradiação os autores observaram morte celular expressiva, com uma sobrevida maior das células hepáticas quando comparadas com as de esôfago, porém sem que ocorra resistência para TFD. Ainda, as nanofibras tiveram um efeito menor de TFD quando comparadas com as soluções do FS, mas ainda assim foram eficazes, o que as credenciam para uso terapêutico e médico.

Henke et al..$^{78}$ (2013), diferente dos demais trabalhos citados até o momento (misturas de solvente bioativos ao polímero), utilizou como meio de inserção do FS a modificação química da superfície das mantas eletrofiadas, nesse caso por sulfonação com ácido clorosulfônico e posteriormente adsorção de 5,10,15,20-tetraquis(1-metilpiridinio-4-il) porfirina (TMPyP). O PS foi o polímero base com a inserção de TEAB. Igualmente a alguns trabalhos já citados, foi notado o desvio no comprimento de onda de absorção para o vermelho, indicado pela interação fotossensibilizador e polímero. Após a adsorção, as fibras mantiveram sua morfologia e tiveram acréscimo no diâmetro. Testes após 70 dias da formulação do material indicaram uma organização do FS e sua agregação. Já para as propriedades fotofísicas o tempo de vida médio do estado triplete foi de 2,3 - $5 \mathrm{~ns}$, tendo dependência direta com a espessura das fibras. Fibras mais espessas forneceram tempos de vida maiores. Os tempos de vida para as fibras também foram maios curtos quando comparados com o FS em solução. Ainda, foi possível constatar a formação de ${ }^{1} \mathrm{O}_{2}$ na superfície do material, indicando que para fotooxidação de substratos se dá apenas com proximidade do alvo. O material também foi capaz de adsorver metais pesados de meio aquático. Por fim, com 2 minutos de irradiação foi denotada uma grande inibição dos microrganismos, onde o mesmo não foi verificado para materiais mantidos no escuro. Além disso, o material é capaz de ser utilizado de uma única vez para foto desinfecção, descontaminação e separação, com efeitos apenas superficiais.

Em 2014, Managa, Antunes e Nyokong ${ }^{79}$ propuseram a síntese porfirina de 5,10,15,20-tetraquis-(4-carboxifenil) gálio (ClGaTcPP) e sua modificação com nanopartículas de platina (PtNPs), ClGaTcPPPtNPs, ambas para posterior eletrofiação e elucidação da eficácia fotodinâmica antimicrobiana. Para isso, foram formuladas soluções PS e as porfirinas separadamente. O polímero puro forneceu diâmetros de fibras de 1 a 2,2 $\mu$ m, já as fibras que continham apenas FS tiveram uma redução branda de 1,2 a 1,9 $\mu \mathrm{m}$. Em contrapartida, ocorreu um acréscimo nos diâmetros quando eletrofiados com porfirina contendo PtNPs, diâmetro esse de 6 a $14 \mu \mathrm{m}$. Além disso, os FS nas fibras possuem o rendimento quântico um pouco menor do que em solução, sendo eles de 0,32 para ClGaTCPP e 0,38 para ClGaTCPP-PtNPs em solução e 0,21 e 0,24 nas fibras, respectivamente. Quando contrapostos frente a $S$. aureus e iluminados, a matriz polimérica pura não obteve efeito fotodinâmico, porém os materiais funcionalizados com as porfirinas obtiveram inibição positiva, sendo que para $\mathrm{ClGaTcPP}$ PtNPs foi verificado um caráter mais acentuado.

Já em 2015, Kim e Michielsen ${ }^{80}$ desenvolveram o estudo com quatro FS da classe dos xantenos, sendo eles: rosa de bengala (RB), Floxina B (FB), azul A (AA) e azul de toluidina (AT) enxertados via polimerização em micro $(17,3 \mu \mathrm{m})$ e nanofibras $(505 \mathrm{~nm}) \mathrm{de}$ Nylon 6,6. Inicialmente, foram preparados materiais a partir do Nylon 6,6 e, posteriormente, os FS foram polimerizados com poli(ácido acrílico) e adicionados nas fibras juntamente com cloreto de 4-(4,6-dimetoxi-1,3,5-triazin-2-il)-4-metilmorfolinio (DMTMM, agente de condensação), fazendo com que os mesmos ficassem na superfícies das fibras. O material obtido foi testado como meio inibitório em zona de inibição e ensaios antifúngicos quantitativos para Aspergillus fumigatus, Aspergillus niger, Trichoderma viride, Penicillium funiculosum e Chaetomium globosum. Como resultado, os autores notaram que tecidos em nanoescala são capazes de gerar uma inibição $30 \%$ superior aos microfibrosos. Materiais em nanoescala contendo RB e FB não permitem o crescimento de microrganismos em torno da amostra, mas não acima. Já as nanofibras contendo AA e AT permitem o crescimento e germinação até no centro do tecido fornecendo pouca inibição. Para microfibras AA e AT permitem o crescimento de colônias de fungos acima do material. Para RB e FB apenas algumas colônias foram observadas. Quando analisados os ensaios quantitativos os autores descrevem uma ordem crescente de taxa de inibição da seguinte forma: $\mathrm{AA}<\mathrm{AT}<\mathrm{FB}<\mathrm{RB}$, sendo explicado pela maior geração de ${ }^{1} \mathrm{O}_{2}$ por $\mathrm{RB}$.

Elashnikov et al. ${ }^{81}$ no ano de 2016, avaliaram a formulação de nanofibras com TPP e com adição de nanopartículas de prata (AgNPs) contra bácterias Enterococcus faecalis (E. faecalis) e Staphylococcus epidermidis (S. epidermidis) utilizando como polímero poli(metilmetacrilato) (PMMA). A solução de PMMA foi adicionada a outra solução de TPP formulando TPP-PMMA e de $\mathrm{AgNO}_{3}$ (TPP-PMMA-AgNPs). Ao final do processo de eletrofiação o material foi submetido a fonte de luz de diodo em torno de $405 \mathrm{~nm}$ para controle da morfologia das AgNPs. ${ }^{82}$ Os autores observaram pelas microscopias eletrônica de varredura e transmissão a agregação das nanopartículas e sua dispersão na superfície das fibras, já pela microscopia confocal a dispersão da TPP nas mesmas. Quando verificada a formação de espécies reativas, as fibras que continham apenas TPP foram mais eficazes do que AgNPs-TPP, explicada pela formação de complexo que restringia a ida da TPP para o estado excitado. Outra observação foi que o material que TPP-PMMA-AGNPs pela irradiação de diodo foi capaz de proteger a TPP de fotobranqueamento, o mesmo não foi visto por TPP-PMMA. Os resultados microbiológicos indicam um efeito bactericida acentuado para as fibras de TPP-PMMA-AgNPs quando comparadas a TPP-PMMA, explicada pela difusão de AgNPs até no escuro.

Stanley et al., ${ }^{83}$ ainda em 2016, verificaram a eficácia e o poder anti-infeccioso de nanofibras de poliacrinonitrila (PAN) combinado com FS a base de porfirina catiônica $\left(\mathrm{Por}^{(+)}\right)$contra um escopo de 
vários microrganismos muito usuais em infecções hospitalares, sendo eles: Staphylococcus aureus, vancomycin-resistant Enterococcus faecium; Escherichia coli, Acinetobacter baumannii e Klebsiella pneumoniae. Ainda, realizaram estudo comparativo ao trabalho de Carpenter ${ }^{84,85}$ na qual a mesma porfirina foi adsorvida em fibras de celulosa natural. Para a eletrofiação das fibras foi utilizada uma solução de PAN e $\mathrm{Por}^{(+)}$. Os autores observaram que as nanofibras, mesmo após lavagem, conseguem reter o FS muito mais do que as fibras de celulose, numa escala três vezes maior. Também, a adição do FS não foi capaz de modificar o diâmetro médio das fibras, sendo essas de $175 \mathrm{~nm}$. O material puro consegue manter uma sobrevida de $100 \%$ dos microrganismos, em contrapartida, os que possuíam FS possuem uma capacidade muito elevada para inativação independente do microrganismo investigado (bactérias gram-negativas, gram-positivas ou vírus) quando excitado no comprimento de onda adequado (30 minutos) e se mostrou superior a trabalhos realizados sem o método de eletrofiação com porfirinas catiônicas modificadas com nanocristais de celulose $\left(\mathrm{Por}^{(+)}-\mathrm{CNCs}\right)^{84}$ ou fibras de celulose, explicada pela área superficial dos materiais avaliados. Os resultados, segundo os cientistas, conferem a esse material um status de grande promissor para aplicação em plataforma anti-infecciosa.

Neste mesmo ano, Kim et al..$^{86}$ utilizou-se do método de eletrofiação em conjunto com a polimerização com intuito de enxertar FS da classe dos xantenos em material eletrofiado em escala de nano e microfibras, diâmetro esse variando de $200 \mathrm{~nm}-5 \mu$ m de Nylon 6,6. Os FS escolhidos dessa vez foram RB, FB, AT e AA que foram polimerizados em poli(ácido acrílico) (PAA) e adsorvidos nas fibras Nylon 6,6. Os microrganismos de estudo da IFMDO foram $P$. cinnamomi, T. viride, A. niger, A. fumigatus, C. globosum, P. funiculosum, e $M$. grisea. Estudos de área superficial indicaram que as nanofibras possuem uma área de $28,8 \mathrm{~m}^{2} \mathrm{~g}^{-1} \mathrm{e}$ as microfibras de $1,41 \mathrm{~m}^{2} \mathrm{~g}^{-1}$. Os testes antifúngicos atestaram o poder de inibição na ordem crescente de $\mathrm{AA}<\mathrm{AT}<\mathrm{FB}<\mathrm{RB}$ que é proporcional à formação de ${ }^{1} \mathrm{O}_{2}$ pelas mantas e as áreas superficiais, ainda quando comparadas as taxas de inibição para as nanofibras com FS ocorre uma inibição superior a $50 \%$, enquanto que para microfibras um pouco superior a $50 \%$. Ainda, para as microfibras contendo AA e AT não foram denotadas inibições dos microrganismos estudados. Outro fator predominante para inativação observada é a característica do microrganismo estudado, uma vez que a membrana lipídica que reveste o microrganismo pode propiciar uma ação fotodinâmica mais ou menos eficiente, no trabalho em questão a $M$. grisea foi a com maior inibição devido ao seu menor invólucro.

Em 2017, El-Khordagui et al.$^{87}$ realizaram estudos pré-clínicos de liberação de FS em ratos imunocomprometidos com feridas. Para isso, os autores eletrofiaram poli(hidroxibutirato) (PHB)/polietilenoglicol (PEG) em uma razão 40/60 com adição de FS azul de metileno (AM). Testes qualitativos de formação de ${ }^{1} \mathrm{O}_{2}$ indicam a formação de espécies reativas pelo material por um período prolongado devido a liberação controlada permitida pelas fibras. Ainda em 1 hora o material é capaz de gerar uma liberação controlada de $42 \%$ do FS a meio tamponante. Observaram também que o material foi capaz de inibir cepas de $S$. aureus e $S$. aureus resistente à meticilina (MRSA) até mesmo no escuro, explicado pelo sequestro dos microrganismos pela malha. Quando estudo in vitro, os ratos que tiveram tratamento com as nanofibras contendo FS tiveram uma contração das feridas superior aos tratados com a solução de AM, além de uma contaminação menor após 15 dias. A epitelização e queratinização das feridas no grupo tratado com as fibras tiveram uma resposta melhor aos tratados com a solução, o que levou a uma cura superior (especialmente nas bordas). Diante disso, os cientistas indicam o material como um grande agente de cura com aplicações promissoras na biomedicina envolvendo feridas.
Os trabalhos mais recentes acerca do assunto, Ma et al. ${ }^{88} \mathrm{e}$ Wang et al. ${ }^{89}$ foram publicados em 2018. O primeiro aborda a eletrofiação de poli(L-ácido láctico) (PLLA) e poli(óxido de etileno) (PEO) em diferentes pesos de 5,10,15,20-tetraquis(4-carboxifenil) porfirina (TCPP, 0-3\%). Foi observado que os diâmetros médios não seguem uma linearidade conforme a adição de FS. A fluorescência confocal indica a distribuição uniforme do FS ao longo de toda a fibra e testes qualitativos de detecção de espécies reativas a formação de ${ }^{1} \mathrm{O}_{2}$. Em testes de liberação de fármaco, os autores observaram que o processo ocorre em duas fases: na primeira a liberação rápida nas 7 horas iniciais e posteriormente a liberação sustentada. No escuro o material possui boa compatibilidade e baixa toxicidade para todas as formulações testadas. Por fim, quando irradiado o material (nesse caso escolhido apenas o de 3\%) e contraposto frente a células tumorais de HeLa foi observada a capacidade de inibição, o mesmo não foi notado para o material sem a adição de FS.

Wang et al. ${ }^{89}$ buscaram a eletrofiação de poli(ácido metacrilato-co-ácido metacrilato) (P(MMA-co-MAA)) juntamente com montmorilonita (MMT), um adsorvente que possui em sua estrutura cátions trocáveis, que confere uma adsorção mais eficiente. Inicialmente foram preparadas soluções com porcentagem em massa diferente de MTT que, posteriormente, tiveram azul de metileno adsorvido. Os autores indicam que com a adição do MTT o diâmetro das fibras aumentam de $564 \mathrm{~nm}$ para $786 \mathrm{~nm}$, com um aumento da carga do FS na superfície de $40 \%$. A absorção do AM tem um leve desvio batocrômico, explicado pela interação tanto com o adsorvente como com o polímero. Quando verificada a atividade fotodinâmica frente microrganismos, os autores denotam que para S. aureus ocorre uma inibição moderada, porém superior a obtida para E. coli, explicada pela membrana envoltória lipídica diferente. Com os resultados, os autores atestam que o AM enxertado no MTT auxilia na TFD devido a localização do FS na superfície das fibras e que um efeito biocida mais pronunciado deve ser obtido com um aumento na carga de FS superficial.

Diante dos trabalhos mostrados, nessa revisão é possível observar a evolução da união das técnicas não só na busca de carga ideal de fotossensibilizadores que forneçam uma TFD/IFMDO desejável, mas também da busca de polímeros que não causem rejeição ao organismo. Ainda, pode ser evidenciado o estudo da inserção dos FS na superfície das nanofibras de maneira que não ocorra a perda das propriedades fotofísicas. De maneira geral, todos os trabalhos obtiveram resultados satisfatórios quando aplicados in vitro e in vivo com grande sucesso, devido a área superficial elevada ofertada pela técnica de eletrofiação, proporcionando um maior contado com oxigênio molecular para a formulação das espécies reativas requeridas. A grande aplicabilidade do material com uso médico como agente de cura de feridas, antimicrobiano e anticancerígeno foi constatada. Vale ressaltar que a busca de novas formulações poliméricas com novos FS é de extrema valia para o mundo científico, uma vez que podem ser formulados materiais com maior poder de TFD/IFMDO.

De maneira resumida, encontram-se dispostos na Tabela 1 os polímeros e FS utilizados, bem como a ordem cronológica de publicações indicadas nesse trabalho.

\section{CONCLUSÃO}

A eletrofiação desde o seu princípio foi capaz de se moldar os vários ramos com grande facilidade e sucesso, entre os quais se destaca o trabalho conjunto com a técnica de terapia fotodinâmica. Como mostrado neste trabalho, a união das fibras eletrofiadas com fotossensibilizadores ofereceu meios inibitórios de crescimento microbiano bacteriológico, fúngico e celular (uso oncológico) com baixa dose de luz e concentração. Dentre os polímeros mais utilizados pode 
Tabela 1. Ordem cronológica de trabalhos que envolvem as técnicas de TFD/IFMDO e eletrofiação

\begin{tabular}{|c|c|c|c|c|}
\hline Ano & Autores & Fotossensibilizador & Polímero & Microrganismo/células \\
\hline 2007 & Mosinger et al..$^{70}$ & ТPP & PU & E. coli \\
\hline 2009 & Mosinger et al..$^{71}$ & TPP, FtZn e ZnTPP & PU & E. coli \\
\hline \multirow[t]{2}{*}{2011} & Jesenská et al. ${ }^{72}$ & TPP & LPU, PS, PCL e PA6 & E. coli \\
\hline & Jeong et al. ${ }^{73}$ & ALA & PVA & Colangiocarcinoma $(\mathrm{CC})$ \\
\hline \multirow[t]{2}{*}{2012} & Arenbergerova et al..$^{74}$ & ТPP & TPU & S. aureus, Pseudomonas aeruginosa e E. coli \\
\hline & Lhotáková et al..$^{75}$ & TPP & PCL e TPU & Poliomavírus e baculovírus recombinante \\
\hline \multirow[t]{3}{*}{2013} & Masilela et al. ${ }^{76}$ & Ft simétricas & PS & S. aureus \\
\hline & Wu et al. ${ }^{77}$ & Pur-18 & PLLA & Carcinoma Hepatocelular e Carcinoma de esôfago \\
\hline & Henke et al. ${ }^{78}$ & TMPуP & PS & E. coli \\
\hline 2014 & Managa, Antunes e Nyokong ${ }^{79}$ & ClGaTcPP e ClGaTcPP-PtNPs & PS & S. aureus \\
\hline 2015 & Kim e Michielsen ${ }^{80}$ & $\mathrm{RB}, \mathrm{FB}, \mathrm{AA}$ e AT & Nylon 6,6 & $\begin{array}{l}\text { Aspergillus fumigatus, Aspergillus niger, Trichoderma } \\
\text { viride, Penicillium funiculosum e Chaetomium globosum }\end{array}$ \\
\hline \multirow[t]{3}{*}{2016} & Elashnikove et al. ${ }^{81}$ & ТPP & PMMA & $\begin{array}{c}\text { Enterococcus faecalis (E. faecalis) e Staphylococcus } \\
\text { epidermidis (S. epidermidis) }\end{array}$ \\
\hline & Stanley et al..$^{83}$ & $\operatorname{Por}^{(+)}$ & PAN & $\begin{array}{l}\text { S. aureus resistente à vancomicina. Enterococcus faecium; } \\
\text { E. coli, Acinetobacter baumannii e Klebsiella pneumonia }\end{array}$ \\
\hline & Kim et al. ${ }^{86}$ & $\mathrm{RB}, \mathrm{FB}, \mathrm{AA}$ e AT & Nylon 6,6 & $\begin{array}{c}\text { P. cinnamomi, } \text { T. viride, A. niger, A. fumigatus, } C \text {. globo- } \\
\text { sum, } \text { P. funiculosum, e M. grisea }\end{array}$ \\
\hline 2017 & El-Khordagui et al. ${ }^{87}$ & $\mathrm{AM}$ & PHB/PEG & S. aureus e S. aureus resistente à meticilina (MRSA) \\
\hline \multirow[t]{2}{*}{2018} & Ma et al. $^{88}$ & TCPP & PLLA/PEO & $\mathrm{HeLa}$ \\
\hline & Wang et al..$^{89}$ & $\mathrm{AM}$ & P(MMA-co-MAA) & S. aureus e E. coli \\
\hline
\end{tabular}

se destacar as formulações de poliuretana e poliestireno. Já entre os fotossensibilizadores, a TPP foi a mais estudada juntamente com as várias vertentes de ftalocianinas. Pode ser observada que a interação do FS com a matriz polimérica, bem como a disposição nas fibras, é de suma importância para obtenção de resultados satisfatórios. Ainda, o diâmetro médio é de grande relevância para difusão do oxigênio molecular e ação fotodinâmica. Em sua maioria os materiais possuem efeitos fotoativos apenas de caráter superficial, sem que ocorra a difusão do FS das fibras. Apesar dos resultados satisfatórios até o momento, apenas uma pequena gama de fotossensibilizadores e polímeros foram utilizados, assim, esta revisão sistemática permite demonstrar que uma abordagem mais profunda ainda é necessária. Espera-se, portanto, que o trabalho seja capaz de auxiliar o planejamento de futuros estudos com novos fármacos fotossensíveis, uma vez que os scaffolds são promissores e possuem grande potencial, principalmente na área de feridas de difícil cicatrização.

\section{AGRADECIMENTOS}

Os autores agradecem a Universidade Estadual de Maringá (UEM) e Universidade Estadual do Oeste do Paraná (Unioeste), ao Grupo Interdisciplinar de Pesquisa Fotoquímica e Eletroquímica Ambiental (GIPeFEA - Unioeste), ao Núcleo de Pesquisa em Sistemas Fotodinâmicos (NUPESP-UEM) e a Coordenação de Aperfeiçoamento de Pessoal de Nível Superior (Capes).

\section{REFERÊNCIAS}

1. Zhang, L.; Webster, T. J.; Nano Today 2009, 4, 66.

2. Karn, B.; Kuiken, T.; Otto, M.; Environ. Health Perspect. 2009, 117, 1813.

3. Lin, G. M.; Shang, M.; Zhang, W. G.; Adv. Mater. Res. 2014, 912-914, 305 .
4. Ferreira, H. S.; Rangel, M. C.; Quim. Nova 2009, 32, 1860.

5. Peres, M. F. S.; Nigoghossian, K.; Primo, F. L.; Saska, S.; Capote, T. S. O.; Caminaga, R. M. S.; Messaddeq, Y.; Ribeiro, S. J. L.; Tedesco, A. C.; J. Braz. Chem. Soc. 2016, 27, 1949.

6. Simplicio, F. I.; Maionchi, F.; Hioka, N.; Quim. Nova 2002, 25, 801.

7. Bastos, M. M.; Boechat, N.; Gomes, A. T. P. C.; Neves, M. G. P. M. S.; Cavaleiro, J. A. S.; Rev. Virtual Quim. 2012, 4, 257.

8. Silva, E. P. O.; Mittmann, J.; Ferreira, V. T. P.; Cardoso, M. A. G.; Beltrame, M.; Lasers Med. Sci. 2014, 30, 347.

9. Nagata, J. Y.; Hioka, N.; Kimura, E.; Batistela, V. R.; Terada, R. S. S.; Graciano, A. X.; Baesso, M. L.; Hayacibara, M. F.; Photodiagn. Photodyn. Ther. 2012, 9, 122.

10. Tucker, N.; Stanger, J. J.; Staiger, M. P.; Razzaq, H.; Hofman, K.; J. Eng. Fibers Fabr. 2012, 7, 155892501200702.

11. Agarwal, S.; Greiner, A.; Wendorff, J. H.; Prog. Polym. Sci. 2013, 38, 963.

12. Braghirolli, D. I.; Steffens, D.; Pranke, P.; Drug Discovery Today 2014, $19,743$.

13. Nascimento, M. L. F.; Araujo, E. S.; Cordeiro, E. R.; de Oliveira, A. H. P.; de Oliveira, H. P.; Recent Pat. Nanotechnol. 2015, 9, 76.

14. Baptista, A. C.; Ferreira, I.; Borges, J. P.; J. Compos. Biodegrad. Polym. 2013, 1,56

15. Akhgari, A.; Heshmati, Z.; Garekani, H. A.; Sadeghi, F.; Sabbagh, A.; Makhmalzadeh, B. S.; Nokhodchi, A.; Colloids Surf., B 2017, 152, 29.

16. Naseri, N.; Algan, C.; Jacobs, V.; John, M.; Oksman, K.; Mathew, A. P.; Carbohydr. Polym. 2014, 109, 7.

17. Qiu, Y.; Zhu, Y.-Y.; Yan, Y.-J.; Chen, N.; Chen, Z.-L.; Blood Coagulation Fibrinolysis 2014, 25, 486.

18. Shafiee, A.; Soleimani, M.; Chamheidari, G. A.; Seyedjafari, E.; Dodel, M.; Atashi, A.; Gheisari, Y.; J. Biomed. Mater. Res., Part A 2011, 99A, 467.

19. Prabhakaran, M. P.; Venugopal, J. R.; Ramakrishna, S.; Biomaterials 2009, 30, 4996 . 
20. Min, B.-M.; Lee, G.; Kim, S. H.; Nam, Y. S.; Lee, T. S.; Park, W. H.; Biomaterials 2004, 25, 1289.

21. Guo, J.; Zhang, Q.; Cai, Z.; Zhao, K.; Sep. Purif. Technol. 2016, 161, 69.

22. Dharani, S.; Mulmudi, H. K.; Yantara, N.; Thu Trang, P. T.; Park, N. G.; Graetzel, M.; Mhaisalkar, S.; Mathews, N.; Boix, P. P.; Nanoscale 2014, 6, 1675.

23. Darbar, D.; Reddy, M. V.; Sundarrajan, S.; Pattabiraman, R.; Ramakrishna, S.; Chowdari, B. V. R.; Mater. Res. Bull. 2016, 73, 369.

24. Kim, D. K.; Hwang, M.; Lagerwall, J. P. F.; J. Polym. Sci., Part B: Polym. Phys. 2013, 51, 855.

25. Rosenberger, A. G.; Dragunski, D. C.; Muniz, E. C.; Módenes, A. N.; Alves, H. J.; Tarley, C. R. T.; Machado, S. A. S.; Caetano, J.; J. Mol. Liq. 2019, 112068

26. Yang, Q.; Wang, D.; Zhang, M.; Gao, T.; Xue, H.; Wang, Z.; Xiong, Z.; J. Alloys Compd. 2016, 688, 1066.

27. Nhan, D. T.; Nhung, N. T. A.; Vien, V.; Trung, N. T.; Cuong, N. D.; Bao, N. C.; Huong, D. Q.; Hien, N. K.; Quang, D. T.; Chem. Lett. 2017, 46, 135 .

28. Serbezeanu, D.; Popa, A. M.; Stelzig, T.; Sava, I.; Rossi, R. M.; Fortunato, G.; Text. Res. J. 2015, 85, 1763.

29. Costa, R. G. F.; de Oliveira, J. E.; de Paula, G. F.; Picciani, P. H. S.; de Medeiros, E. S.; Ribeiro, C.; Mattoso, L. H. C.; Polímeros 2012, 22 , 178.

30. Cui, W.; Zhou, Y.; Chang, J.; Sci. Technol. Adv. Mater. 2010, 11, 014108.

31. da Silva, T. T.; Cesar, G. B.; Francisco, C. P.; Mossini, G. G.; Hoshino, L. V. C.; Sato, F.; Radovanovic, E.; Agostini, D. L. S.; Caetano, W.; Hernandes, L.; Matioli, G.; J. Appl. Polym. Sci. 2019, 48415.

32. Persano, L.; Camposeo, A.; Tekmen, C.; Pisignano, D.; Macromol. Mater. Eng. 2013, 298, 504.

33. Yarin, A. L.; Koombhongse, S.; Reneker, D. H.; J. Appl. Phys. 2001, 90 4836.

34. Costa, R. G. F.; de Oliveira, J. E.; de Paula, G. F.; Picciani, P. H. S.; de Medeiros, E. S.; Ribeiro, C.; Mattoso, L. H. C.; Polímeros 2012, 22 , 170.

35. Kriegel, C.; Arrechi, A.; Kit, K.; McClements, D. J.; Weiss, J. F.; Crit. Rev. Food Sci. Nutr. 2008, 48, 775.

36. Ramakrishna, S.; Fujihara, K.; Teo, W.-E.; Lim, T.-C.; Ma, Z.; An Introduction to Electrospinning and Nanofibers; World Scientific: Singapore, 2005.

37. Balaji, A.; Vellayappan, M. V.; John, A. A.; Subramanian, A. P.; Jaganathan, S. K.; Supriyanto, E.; Razak, S. I. A.; $R S C A d v$. 2015, 5 , 57984.

38. Bhardwaj, N.; Kundu, S. C.; Biotechnol. Adv. 2010, 28, 325.

39. Auras, R.; Harte, B.; Selke, S.; Macromol. Biosci. 2004, 4, 835.

40. Ning, J.; Zhang, X.; Yang, H.; Xu, Z.-L.; Wei, Y.-M.; Fibers Polym. 2016, 17, 21.

41. Canbolat, M. F.; Celebioglu, A.; Uyar, T.; Colloids Surf., B 2014, 115, 15

42. Chan, C. M.; Ko, T. M.; Hiraoka, H.; Surf. Sci. Rep. 1996, $24,1$.

43. Surucu, S.; Masur, K.; Sasmazel, H. T.; Von Woedtke, T.; Weltmann, K. D.; Appl. Surf. Sci. 2016, 385, 400.

44. Thielke, M. W.; Bruckner, E. P.; Wong, D. L.; Theato, P.; Polymer (Guildf) 2014, 55, 5596.

45. Huang, L.; Arena, J. T.; Manickam, S. S.; Jiang, X.; Willis, B. G.; McCutcheon, J. R.; J. Memb. Sci. 2014, 460, 241

46. Gold, M. H.; Dermatol. Clin. 2007, 25, 1.

47. Ormond, A. B.; Freeman, H. S.; Materials 2013, 6, 817.

48. Allison, R. R.; Sibata, C. H.; Photodiagn. Photodyn. Ther. 2010, 7, 61.

49. Allison, R. R.; Mota, H. C.; Sibata, C. H.; Photodiagn. Photodyn. Ther. 2004, 1, 263

50. Castano, A. P.; Demidova, T. N.; Hamblin, M. R.; Photodiagn. Photodyn. Ther. 2004, 1, 279.
51. Castano, A. P.; Demidova, T. N.; Hamblin, M. R.; Photodiagn. Photodyn. Ther. 2005, 2, 1.

52. Castano, A. P.; Demidova, T. N.; Hamblin, M. R.; Photodiagn. Photodyn. Ther. 2005, 2, 91.

53. Dai, T.; Fuchs, B. B.; Coleman, J. J.; Prates, R. A.; Astrakas, C.; St. Denis, T. G.; Ribeiro, M. S.; Mylonakis, E.; Hamblin, M. R.; Tegos, G. P.; Front. Microbiol. 2012, 3, 120.

54. Agostinis, P.; Berg, K.; Cengel, K. A.; Foster, T. H.; Girotti, A. W.; Gollnick, S. O.; Hahn, S. M.; Hamblin, M. R.; Juzeniene, A.; Kessel, D.; Korbelik, M.; Moan, J.; Mroz, P.; Nowis, D.; Piette, J.; Wilson, B. C.; Golab, J.; Ca-Cancer J. Clin. 2011, 61, 250.

55. Dolmans, D. E. J. G. J.; Fukumura, D.; Jain, R. K.; Nat. Rev. Cancer 2003, 3, 380 .

56. Machado, A. E. H.; Quim. Nova 2000, 23, 273

57. Allison, R. R.; Mota, H. C.; Bagnato, V. S.; Sibata, C. H. B.; Photodiagn. Photodyn. Ther. 2008, 5, 19.

58. Pellosi, D. S.; Tessaro, A. L.; Moret, F.; Gaio, E.; Reddi, E.; Caetano, W.; Quaglia, F.; Hioka, N.; J. Photochem. Photobiol., A 2016, 314, 143.

59. Dai, T.; Huang, Y. Y.; Hamblin, M. R.; Photodiagn. Photodyn. Ther. 2009, 6, 170.

60. Buzzá, H. H.; Paula, A.; Dirceu, J.; Filho, V.; Patricia, D.; Roberto, J.; Inada, N. M.; Moriyama, L. T.; Kurachi, C.; Bagnato, V. S.; Photodiagn. Photodyn. Ther. 2015, 6, 261.

61. Sbeghen, M. R.; Voltarelli, E. M.; Campois, T. G.; Kimura, E.; Arisitides, S. M. A.; Hernandes, L.; Caetano, W.; Hioka, N.; Lonardoni, M. V. C.; Silveira, T. G. V.; J. Lasers Med. Sci. 2015, 6, 106.

62. Nesi-Reis, V.; Navasconi, T. R.; Lera-Nosone, D. S. S. L.; Oliveira, E. L.; Barbosa, P. M.; Caetano, W.; Silveira, T. G. V.; Aristides, S. M. A.; Hioka, N.; Lonardoni, M. V. C.; Photodiagn. Photodyn. Ther. 2018, 21, 239.

63. Gad, F.; Zahra, T.; Hasan, T.; Hamblin, M. R.; Antimicrob. Agents Chemother. 2004, 48, 2173.

64. Wainwright, M.; J. Antimicrob. Chemother. 1998, 42, 13.

65. Chen, C.-P.; Chen, C.-T.; Tsai, T.; Photochem. Photobiol. 2012, 88, 570.

66. Perussi, J. R.; Quim. Nova 2007, 30, 988

67. Johnson, E. M.; Flannagan, S. E.; Sedgley, C. M.; J. Endod. 2006, 32, 946

68. de Morais, F. A. P.; Enumo, A.; Gonçalves, R. S.; Cesar, G. B.; Miranda, N.; Vilsinski, B. H.; da Silva, R. C.; Nakamura, C. V.; Hioka, N.; Caetano, W.; Photochem. Photobiol. Sci. 2019, 18, 487.

69. da Silva Junior, R. C.; Campanholi, K. S. S.; de Morais, F. A. P.; Pozza, M. S. S.; dos Santos, G. T.; Hioka, N.; Caetano, W.; Dyes Pigm. 2019. 167, 204.

70. Mosinger, J.; Jirsák, O.; Kubát, P.; Lang, K.; Mosinger, B.; J. Mater. Chem. 2007, 17, 164

71. Mosinger, J.; Lang, K.; Kubát, P.; Sýkora, J.; Hof, M.; Plíštil, L.; Mosinger, B.; J. Fluoresc. 2009, 19, 705.

72. Jesenská, S.; Plíštil, L.; Kubát, P.; Lang, K.; Brožová, L.; Popelka, Š.; Szatmáry, L.; Mosinger, J.; J. Biomed. Mater. Res., Part A 2011, 99A, 676.

73. Jeong, Y.-I.; Yoo, C.; Kim, C.-W.; Chung, C.-W.; Kang, D. H.; Int. J. Nanomed. 2012, 7, 1997.

74. Arenbergerova, M.; Arenberger, P.; Bednar, M.; Kubat, P.; Mosinger, J.; Exp. Dermatol. 2012, 21, 619.

75. Lhotáková, Y.; Plî́til, L.; Morávková, A.; Kubát, P.; Lang, K.; Forstová, J.; Mosinger, J.; PLoS One 2012, 7, e49226.

76. Masilela, N.; Kleyi, P.; Tshentu, Z.; Priniotakis, G.; Westbroek, P.; Nyokong, T.; Dyes Pigm. 2013, 96, 500.

77. Wu, H. M.; Chen, N.; Wu, Z. M.; Chen, Z. L.; Yan, Y. J.; J. Biomater. Appl. 2013, 27, 773 .

78. Henke, P.; Lang, K.; Kubát, P.; Sýkora, J.; Šlouf, M.; Mosinger, J.; ACS Appl. Mater. Interfaces 2013, 5, 3776.

79. Managa, M.; Antunes, E.; Nyokong, T.; Polyhedron 2014, 76, 94. 80. Kim, J. R.; Michielsen, S.; J. Photochem. Photobiol., B 2015, 150, 50 
81. Elashnikov, R.; Lyutakov, O.; Ulbrich, P.; Svorcik, V.; Mater. Sci. Eng., C 2016, 64, 229.

82. Stamplecoskie, K. G.; Scaiano, J. C.; J. Am. Chem. Soc. 2010, 132, 1825 .

83. Stanley, S.; Scholle, F.; Zhu, J.; Lu, Y.; Zhang, X.; Situ, X.; Ghiladi, R.; Nanomaterials 2016, 6, 77.

84. Carpenter, B. L.; Feese, E.; Sadeghifar, H.; Argyropoulos, D. S.; Ghiladi, R. A.; Photochem. Photobiol. 2012, 88, 527.

85. Carpenter, B. L.; Scholle, F.; Sadeghifar, H.; Francis, A. J.; Boltersdorf,
J.; Weare, W. W.; Argyropoulos, D. S.; Maggard, P. A.; Ghiladi, R. A.; Biomacromolecules 2015, 16, 2482.

86. Kim, J. R.; Michielsen, S.; Nanomaterials 2016, 6, 243.

87. El-Khordagui, L.; El-Sayed, N.; Galal, S.; El-Gowelli, H.; Omar, H.; Mohamed, M.; Int. J. Pharm. 2017, 520, 139.

88. Ma, F.; Yuan, C. W.; Ren, X. X.; You, C. J.; Cao, J. H.; Wu, D. Y.; J. Photochem. Photobiol., A 2018, 355, 267.

89. Wang, Q.; Chen, W.; Zhang, Q.; Ghiladi, R. A.; Wei, Q.; Appl. Surf. Sci. 2018, 457, 247. 